\title{
Diagnóstico qualiquantitativo da arborização urbana da cidade de Monte Alegre, Pará, Brasil
}

\author{
Quanti-qualitative inventory of urban afforestation in the city of Monte Alegre, \\ Pará, Brazil
}

\author{
Washington Jonathan Lima Bacelar', Maurício Möller Parry ${ }^{\mathrm{II}}$, \\ Raírys Cravo Herrera ${ }^{\mathrm{III}}$, Isadora Fernandes de França ${ }^{\mathrm{III}}$, \\ Stérphane Matos Parry ${ }^{\mathrm{I}}$
}

\begin{abstract}
Resumo
Foi realizado o levantamento das condições da arborização urbana da cidade de Monte Alegre, cidade paraense que não dispõe de Plano Diretor, faltando assim um planejamento de arborização e um diagnóstico sistematizado. O diagnóstico qualiquantitativo das espécies foi realizado com a utilização de planilhas estruturadas, identificando-se benefícios e problemas relacionados aos seus plantios. Foram identificadas 2.938 plantas de 64 espécies, distribuídas em 56 gêneros e 25 famílias botânicas. A espécie mais frequente foi o Ipê-amarelo (Handroanthus serratifolius (Vahl.) S.O. Grose), com 312 espécimes que representa 10,6\% das árvores da cidade. A família botânica Fabaceae foi a mais representativa com 11 espécies $(17,2 \%)$ e a mais numerosa com 518 indivíduos $(17,6 \%)$. Identificou-se que $(14,4 \%)$ das árvores apresentam conflitos com a fiação elétrica, $(4 \%)$ apresentam conflitos com a iluminação pública e $(1,7 \%)$ com a sinalização de trânsito. Constatou-se ainda grande diversidade de espécies presentes nas vias públicas, as quais podem ter sido plantadas por parte da Prefeitura Municipal de Monte Alegre, bem como pela ação da população. Diante disso, considera-se indispensável o planejamento da arborização urbana e a realização de um Plano Diretor no município, prevendo critérios e técnicas adequadas de plantios e manutenções, para, assim, possibilitar a efetivação dos benefícios esperados.
\end{abstract}

Palavras-chave: Planejamento urbano; Espaços públicos; Diversidade de espécies vegetais

\footnotetext{
Licenciado em Ciências Biológicas, Graduado, Professor da Secretaria Municipal de Educação, Av. Aviador Pinto Martins, 342, Serra Ocidental, CEP 68220-000, Monte Alegre (PA), Brasil. jonathanbacelar@gmail.com (ORCID: 0000-0002-8527-374X)

II Engenheiro Agrônomo, Dr., Professor da Faculdade de Ciências Biológicas, da Universidade Federal do Pará, Rua Coronel José Porfírio, 2515, Esplanada do Xingu, CEP 68372-040, Altamira (PA), Brasil. mauricioparry@yahoo.com.br (ORCID: 0000-0002-0516-0674)

III Bacharel em Biologia, Dra., Professora da Faculdade de Ciências Biológicas, da Universidade Federal do Pará, Rua Coronel José Porfírio, 2515, Esplanada do Xingu, CEP 68372-040, Altamira (PA), Brasil. rairys@gmail.com (ORCID: 0000-0002-9699-8359)

III Bacharel em Biologia, Dra., Professora da Faculdade de Ciências Biológicas, da Universidade Federal do Pará, Rua Coronel José Porfírio, 2515, Esplanada do Xingu, CEP 68372-040, Altamira (PA), Brasil. isa_bio@yahoo.com.br (ORCID: 0000-0002-6917-1970)

IV Licenciada em Ciências Biológicas, Ma., Professora da Universidade Serra Dourada, Rua Elias Leitão, 863, Ibiza, CEP 68376-705, Altamira (PA), Brasil.ster_bio@yahoo.com.br(ORCID: 0000-0001-9205-4409)
} 


\begin{abstract}
The survey was carried out in the conditions of urban afforestation in the city of Monte Alegre, Pará, which has no master plan, missing afforestation planning and a systematic diagnosis. Quanti-qualitative diagnosis of the species was conducted with the use of structured spreadsheets, identifying benefits and problems related to their plantations. There were 2,938 plants identified among 64 species, distributed in 56 genuses and belonging to 25 botanical families. The most frequent species was the Yellow Ipê (Handroanthus serratifolius (Vahl.) S.O. Grose), with 312 specimen, which represented $10.6 \%$ of the city's trees. The botanical family Fabaceae was the most represented with 11 species $(17,2 \%)$ and the most numerous with 518 individuals $(17,6 \%)$ used in afforestation. It was identified that many trees cause conflicts with electrical wiring (14.4\%) while a few others conflict with street public lighting (4\%) and traffic signs (1.7\%). It was noted the presence of a diversification of species present on public roads, which resulted from the participation of the City Hall of Monte Alegre. Given this, planning of urban forestation and development of a city's master plan are considered essential, in order to provide appropriate criteria and techniques of planting and maintenance to enable the implementation of the expected benefits.
\end{abstract}

Keywords: Urban planning; Public spaces; Species diversity

\title{
Introdução
}

No Brasil, os jardins começam a ser implantados somente no final do século XIX e início do século $\mathrm{XX}$, depois de muita resistência da população, quando houve o reconhecimento da importância da vegetação no espaço urbano como fator de bem estar, consolidando a criação das áreas verdes (SEGAWA, 2010).

A arborização urbana merece uma atenção cada vez maior em função dos benefícios e até mesmo dos problemas que se apresentam em função da presença da árvore no contexto da cidade. Atualmente, na tentativa de minimizar os impactos ambientais causados pelo crescimento das cidades, os gestores buscam por alternativas que proporcionem uma melhor qualidade de vida à população. Dentre os benefícios da arborização, pode-se dizer que essa é responsável pela redução do calor, da poluição atmosférica, da poluição sonora e o embelezamento da paisagem dos centros urbanos, além disso, funciona como corredor ecológico fornecendo abrigo, refúgio e alimentos para quase todos os animais (SILVA; CARDOSO; RAPHAEL, 2012).

No entanto, quando a arborização da cidade é feita sem o devido planejamento, pode acarretar em inúmeros prejuízos, visto que a incorporação de árvores inadequadas à estrutura urbana pode gerar conflitos com os equipamentos urbanos como fiações elétricas, encanamentos, calhas, calçamentos, muros, e postes de iluminação. Esses problemas são comuns nas cidades brasileiras e causam, na maioria das vezes, um manejo inadequado e prejudicial às árvores (RIBEIRO, 2009; PARRY et al., 2012; SILVA et al., 2018).

Assim sendo, para que a arborização urbana proporcione os benefícios necessários, é indispensável o planejamento. Tudo deve ser feito seguindo as características botânicas das espécies mescladas com os espaços físicos a elas disponíveis. As árvores no perímetro urbano são constantemente ameaçadas pelo descaso da população e do Poder Público através de suas instalações (rede elétrica, de água e esgoto, por exemplo). É necessário que as prefeituras sigam as orientações contidas no planejamento da arborização, desde a escolha da espécie até o plantio e manutenção das árvores, para que os serviços prestados à população não sejam prejudicados e árvores não tenham que ser sacrificadas (BIONDI; LEAL, 2008; BRASIL, 2008; LIMA; SILVA JÚNIOR, 2010). Em muitas cidades brasileiras esse planejamento não está acontecendo de forma adequada, assim, surgem os problemas com a infraestrutura daquela localidade, como a pavimentação, rede elétrica, telefônica, de esgoto e sinalização (MILANO, 1984; PARRY et al., 2012; SILVA et al., 2018).

Dessa forma, é indispensável que os atores sociais envolvidos, como o poder público municipal e os demais setores responsáveis pela arborização urbana atuem de forma conjunta, de acordo com as legislações pertinentes, visando o bem estar da população e o bom uso de seus 
serviços instalados (PARRY et al., 2012; SILVA et al., 2018). Além disso, é importante que haja mais participação e comprometimento da população na inserção e na conservação da arborização. Assim, de fato, poderão ser evitados problemas, prejuízos e acidentes, transformando o ambiente urbano o mais agradável possível ao cidadão (SEGAWA, 2010).

Cabe ressaltar que a Secretaria Municipal de Meio Ambiente, Agricultura, Pesca e Turismo de Monte Alegre não dispõe de um Plano Diretor de Arborização Urbana, no entanto esse documento já deveria ter sido elaborado, pois de acordo com o Estatuto das Cidades (Lei $\mathrm{n}^{\circ} 10.257$, de 10 de Julho de 2001) todas as cidades com mais de 20 mil habitantes devem possuir o seu Plano Diretor de Arborização Urbana (BRASIL, 2008), o que certamente compete ao município de Monte Alegre, já que possui 56.391 habitantes (IBGE, 2016). Dessa forma, Monte Alegre não possui nenhum planejamento de arborização urbana, assim como nunca foi realizado um diagnóstico sistematizado nesse cenário. Desse modo, este estudo objetivou realizar um levantamento qualiquantitativo da arborização urbana da cidade de Monte Alegre, como também identificar os benefícios e os problemas relacionados ao seu plantio, com o intuito de fornecer subsídios para um futuro planejamento da arborização municipal.

\section{Material e métodos}

\section{Área de estudo}

O estudo foi realizado na cidade de Monte Alegre, Estado do Pará, localizada nas seguintes coordenadas geográficas: Latitude $02^{\circ} 00^{\prime} 28^{\prime \prime} \mathrm{S}$ e Longitude $54^{\circ} 04^{\prime} 09^{\prime \prime} \mathrm{W}$. Segundo Carvalho (2015), Monte Alegre localiza-se na Amazônia brasileira, na mesorregião do Baixo Amazonas, no Noroeste do Estado do Pará, à margem esquerda do rio Amazonas (Figura 1).

\section{Figura 1 - Localização do município de Monte Alegre (PA), às margens do rio Amazonas}

Figure 1 - Location of the city of Monte Alegre (PA) on the shores of the Amazon river

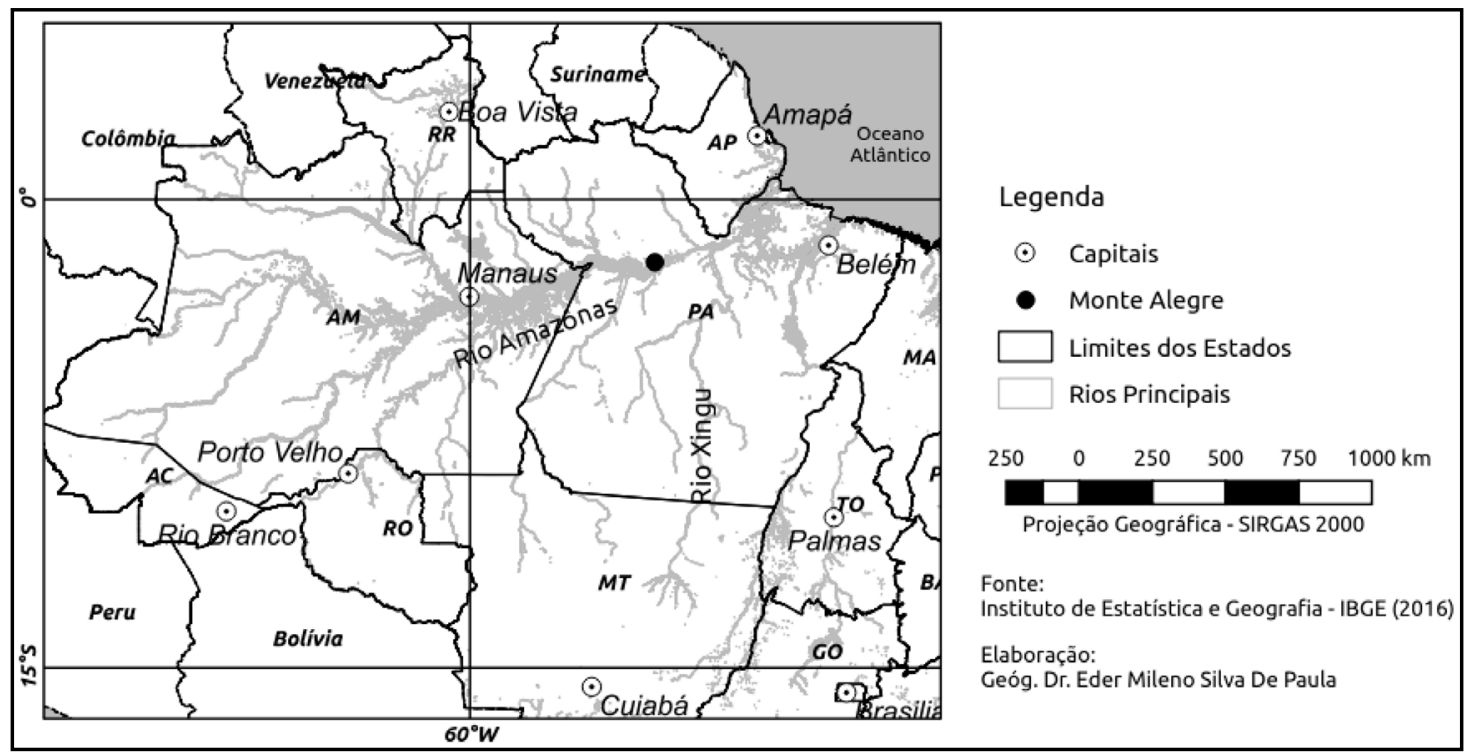

Fonte: De Paula (2019), adaptado de IBGE (2016)

O município de Monte Alegre ocupa uma área de 21.703,027 $\mathrm{km}^{2}$ no Oeste do Pará. De acordo com dados do IBGE (2016) a estimativa de sua população é de 56.391 habitantes, com densidade demográfica de 2,6 hab./ $\mathrm{km}^{2}$. Possui clima do tipo Am, segundo Köppen, onde 
predomina a vegetação de floresta de Terra Firme densa e latifoliada. A estação mais chuvosa abrange os meses de dezembro a março e o período mais seco compreende os meses de junho a setembro (CARVALHO, 2015).

\section{Coleta de Material botânico e análise dos dados}

Para o levantamento qualiquantitativo da vegetação presente na arborização de Monte Alegre, realizou-se um diagnóstico arbóreo-arbustivo, no ano de 2017, efetivado por meio do levantamento total das espécies vegetais presentes nas vias públicas de todos os bairros da cidade, a citar: Centro, Cidade Alta, Cidade Baixa, Curaxi, Curaxi II, Camarazinho, Curitanfã, Nova Olinda, Nova União, Papagaio, Pajuçara, Planalto, Terra Amarela, Serra Ocidental, Serra Oriental, Surubeju e Turu.

Durante o levantamento in loco utilizou-se de uma planilha específica proposta por Parry et al. (2012) e já aplicada por Silva et al. (2018), com os seguintes questionamentos sobre as árvores: nome vernacular; espécie; altura; diâmetro de copa; circunferência do caule a altura do peito (CAP); situação dos caules e das copas (equilibrados ou não); afloramento de raiz (sim ou não); fases do desenvolvimento (vegetativo, floração ou frutificação); fitossanidade (com diferentes graus de severidade do ataque de pragas e/ou doenças); necessidade de poda (se em conflito com a fiação, iluminação ou sinalização de trânsito ou se necessitando de poda de manutenção); afastamento predial (muros, casas e meio fio); tamanho das calçadas e áreas livres (canteiros). Para a determinação das medidas das plantas e dos espaços físicos (canteiros, calçadas, ruas), utilizou-se de trena de 10 metros e de 50 metros, vara fina medindo 2 metros de comprimento e prancheta.

Os resultados obtidos estão apresentados em uma tabela com os seguintes dados para as espécies: nomes vernaculares e científicos, famílias, origem, número de plantas por espécie e densidade relativa (Dr). A Dr revela, em porcentagem, a participação de cada espécie em relação ao número total de indivíduos de todas as espécies. Neste estudo foi feito o levantamento das áreas de distribuição geográfica das espécies, com ênfase nas nomenclaturas utilizadas por Lima e Silva Júnior (2010) e Flora do Brasil (2020).

Para a coleta do material botânico herborização e incorporação (herbário) foram utilizadas as metodologias e técnicas botânicas usuais especializadas descritas por Fidalgo e Bononi (1989).

Os espécimes identificados foram qualificados em famílias, de acordo com a classificação Angiosperm Phylogeny Group (APG IV, 2016), e para averiguação da grafia correta dos binômios e seus respectivos autores foram autenticados conforme informações contidas nas bases de dados da Flora do Brasil 2020, Reflora e MOBOT 2019. Nessa perspectiva, para evitar possíveis confusões botânicas foi utilizado o Guia de Identificação organizado por Campos Filho (2009) e a confirmação das espécies foi realizada através de consulta a Lista de Espécies da Flora do Brasil (FORZZA; LEITMAN; COSTA, 2010).

\section{Resultados e discussão}

\section{Análise florística}

O levantamento da arborização urbana realizado em Monte Alegre identificou a presença de 2.938 plantas arbóreas, arvoretas e arbustivas. As plantas pertencem a 64 espécies, distribuídas em 56 gêneros e 25 famílias botânicas, conforme consta na Tabela 1. Fabaceae foi a família botânica mais numerosa (518 indivíduos ou 17,6\%) e a que registrou o maior número de espécies (11) que correspondem a $17,2 \%$ do total das espécies identificadas na cidade. Outras famílias com altas frequências foram: Bignoniaceae, com 377 indivíduos (12,8\%); Anacardiaceae, com 373 indivíduos (12,7\%); Myrtaceae, com 346 indivíduos (11,8\%); Meliaceae, com 293 indivíduos (10\%) 
das plantas utilizadas na arborização urbana de Monte Alegre.

Tabela 1 - Espécies vegetais, famílias botânicas, origem, número de indivíduos e densidade relativa de espécies incluídas no levantamento da arborização urbana de Monte Alegre, Pará, Brasil

Table 1 - Plant species, botanical families, origin, number of individuals and relative density of species included in the inventory carried out in Monte Alegre, Pará, Brazil

\begin{tabular}{|c|c|c|c|c|c|}
\hline Nomes Científicos & $\begin{array}{c}\text { Nomes } \\
\text { Vernaculares }\end{array}$ & Famílias & Origem & $\begin{array}{c}\mathrm{N}^{\circ} \mathrm{de} \\
\text { plantas }\end{array}$ & $\operatorname{Dr}(\%)$ \\
\hline $\begin{array}{l}\text { Handroanthus serratifolius (Vahl.) S. O. } \\
\text { Grose }\end{array}$ & Ipê-amarelo & Bignoniaceae & $\begin{array}{l}\mathrm{Am}, \mathrm{Ce} \\
\mathrm{Mg}\end{array}$ & 312 & 10,61 \\
\hline Azadirachta indica A. Juss. & $\mathrm{Nim}$ & Meliaceae & $\mathrm{E}$ & 281 & 9,60 \\
\hline $\begin{array}{l}\text { Syzygium malaccense (L.) Merr \& L. M. } \\
\text { Perry }\end{array}$ & Jambeiro & Myrtaceae & $\mathrm{E}$ & 181 & 6,20 \\
\hline Mangifera indica $\mathrm{L}$. & Mangueira & Anacardiceae & $\mathrm{E}$ & 155 & 5,30 \\
\hline Anacardium occidentale $\mathrm{L}$. & Cajueiro & Anacardiceae & $\begin{array}{l}\text { Am, Ma, } \\
\quad \mathrm{Mg}\end{array}$ & 155 & 5,30 \\
\hline Delonix regia (Hook.) Raf. & Flamboyant & Fabaceae & $\mathrm{E}$ & 126 & 4,30 \\
\hline Licania tomentosa Benth. & Oiti & Chrysobalanaceae & $\mathrm{Ca}$ & 98 & 3,40 \\
\hline Cassia fistula $\mathrm{L}$. & Chuva-de-ouro & Fabaceae & $\mathrm{E}$ & 94 & 3,20 \\
\hline Andira inermis (W. Wright) DC. & Andira-uchi & Fabaceae & $\mathrm{Am}, \mathrm{Ce}$ & 94 & 3,20 \\
\hline Psidium guayava L. & Goiabeira & Myrtaceae & $\mathrm{Mg}$ & 85 & 2,90 \\
\hline Ficus benjamina $\mathrm{L}$. & Ficus & Moraceae & $\mathrm{E}$ & 84 & 2,85 \\
\hline Bougainvillea spectabillis Willd. & Boungainvilea & Nictaginaceae & $\mathrm{E}$ & 63 & 2,20 \\
\hline Roystonea oleracea (Jacq.) O. F. Cook & $\begin{array}{l}\text { Palmeira- } \\
\text { imperial }\end{array}$ & Arecaceae & $\mathrm{E}$ & 56 & 1,90 \\
\hline Byrsonima crassifolia (L.) Rich. & Murici & Malpighiaceae & $\mathrm{Am}, \mathrm{Ca}$ & 55 & 1,87 \\
\hline Euterpe oleraceae Mart. & Açaizeiro & Arecaceae & Am & 49 & 1,70 \\
\hline Cenostigma macrophyllum Tul. & Macharimbé & Fabaceae & Am & 49 & 1,70 \\
\hline Plumeria pudica Jacq. & Buquê-de-noiva & Apocynaceae & $\mathrm{E}$ & 47 & 1,60 \\
\hline Prosopis juliflora (Sw.) DC. & Algaroba & Fabaceae & $\mathrm{Ca}$ & 46 & 1,56 \\
\hline Carica papaya $\mathrm{L}$. & Mamoeiro & Caricaceae & $\mathrm{E}$ & 46 & 1,56 \\
\hline Tabebuia roseoalba (Ridl.) Sandwith & Ipê-branco & Bignoniaceae & $\mathrm{Mg}, \mathrm{Ms}$ & 44 & 1,50 \\
\hline Citrus limon (L.) Burm. f. & Limoeiro & Rutaceae & $\mathrm{E}$ & 42 & 1,45 \\
\hline Corymbia citriodora Hill \& Johnson & Eucalipto & Myrtaceae & $\mathrm{E}$ & 41 & 1,40 \\
\hline Terminalia catappa $\mathrm{L}$. & Castanhola & Combretaceae & $\mathrm{E}$ & 37 & 1,25 \\
\hline $\begin{array}{l}\text { Livistona chinensis (N. J. Jacquin) R. } \\
\text { Bronw ex. Mart. }\end{array}$ & Palmeira-leque & Arecaceae & $\mathrm{E}$ & 36 & 1,22 \\
\hline Spondias mombin L. & Taperebá & Anacardiaceae & $\mathrm{Am}, \mathrm{Ce}$ & 36 & 1,22 \\
\hline
\end{tabular}


Tabela 1 - Continuação ...

Table 1 - Continuation ...

\begin{tabular}{|c|c|c|c|c|c|}
\hline Nomes Científicos & $\begin{array}{c}\text { Nomes } \\
\text { Vernaculares }\end{array}$ & Famílias & Origem & $\begin{array}{c}\mathbf{N}^{\circ} \text { de } \\
\text { plantas }\end{array}$ & $\operatorname{Dr}(\%$ \\
\hline Bauhinia variegata $L$. & Pata-de-vaca & Fabaceae & E & 34 & 1,20 \\
\hline Cocus nucifera $\mathrm{L}$. & Coqueiro & Arecaceae & $\mathrm{Am}, \mathrm{Ma}$ & 33 & 1,15 \\
\hline Syzygium cumini (L.) Skeels. & Jambolão & Myrtaceae & E & 31 & 1,05 \\
\hline Theobroma cacao L. & Cacaueiro & Malvaceae & E & 29 & 1,00 \\
\hline Epiphyllum oxipetalum (DC) Haworth & Dama-da-noite & Cactaceae & $\mathrm{Ma}, \mathrm{Ce}$ & 27 & 0,91 \\
\hline $\begin{array}{l}\text { Libidibia ferrea (Mart. ex Tul.) L. P. } \\
\text { Queiroz }\end{array}$ & Jucá & Fabaceae & $\mathrm{Ce}$ & 27 & 0,91 \\
\hline Citrus sinensis (L.) Osbeck & Laranjeira & Rutaceae & $\mathrm{E}$ & 26 & 0,90 \\
\hline Rinicius communis $\mathbf{L}$. & Mamona & Euphorbiaceae & $\mathrm{E}$ & 26 & 0,90 \\
\hline Persea americana Mill. & Abacateiro & Lauraceae & E & 25 & 0,85 \\
\hline Citrus deliciosa Ten. & Tangerina & Rutaceae & E & 25 & 0,85 \\
\hline Sapindus saponaria $\mathbf{L}$. & Saboneteira & Sapindaceae & $\mathrm{Mg}, \mathrm{Ms}$ & 24 & 0,81 \\
\hline Jatropha curcas $\mathbf{L}$. & Pião-branco & Euphorbiaceae & E & 21 & 0,71 \\
\hline $\begin{array}{l}\text { Handroanthus impetiginosus (Mart. ex } \\
\text { DC.) Mattos }\end{array}$ & Ipê-roxo & Bignoniaceae & $\mathrm{Ma}$ & 21 & 0,71 \\
\hline Malpighia glabra $\mathrm{L}$. & Acerola & Malpighiaceae & E & 21 & 0,71 \\
\hline $\begin{array}{l}\text { Inga vera (Willd.) subsp. Affinis (DC.) } \\
\text { T.D Penn }\end{array}$ & Ingá & Fabaceae & $\mathrm{Ma}$ & 20 & 0,70 \\
\hline Spondias purpurea $\mathbf{L}$. & Ciriguela & Anacardiaceae & $\mathrm{Ca}$ & 18 & 0,61 \\
\hline Cinnamomum zeylanicum J. Presl & Canela & Lauraceae & E & 18 & 0,61 \\
\hline Genipa americana $\mathrm{L}$. & Jenipapo & Rubiaceae & $\begin{array}{l}\mathrm{Ma}, \mathrm{Mg}, \\
\mathrm{Ms}\end{array}$ & 16 & 0,55 \\
\hline Ormosia paraenses Ducke & Tento & Fabaceae & $\mathrm{Am}$ & 15 & 0,51 \\
\hline Talisia esculenta (St.-Hil) Radlk & Pitomba & Sapindaceae & Am, Ma & 15 & 0,51 \\
\hline Averrhoa carambola $\mathrm{L}$. & Carambola & Oxalidaceae & $\mathrm{E}$ & 14 & 0,50 \\
\hline Gmelina arborea Roxb. & Gmelina & Verbenaceae & $\mathrm{E}$ & 13 & 0,45 \\
\hline Swietenia macrophylla King. & Mogno & Meliaceae & $\mathrm{Am}$ & 12 & 0,40 \\
\hline Ceiba pentandra (L.) Gaerth & Sumaúma & Malvaceae & $\mathrm{Am}$ & 12 & 0,40 \\
\hline Annona squamosa $\mathrm{L}$. & Ata & Annonaceae & $\mathrm{E}$ & 12 & 0,40 \\
\hline Caryo taurens $\mathbf{L}$. & $\begin{array}{l}\text { Palmeira-rabo- } \\
\text { de-peixe }\end{array}$ & Arecaceae & E & 11 & 0,37 \\
\hline Schinus terebinthifolius Raddi. & Aroeira-vermelha & Anacardiaceae & Ms & 09 & 0,30 \\
\hline $\begin{array}{l}\text { Dypsis lutescens (H. Wendl.) Beentje \& } \\
\text { J. Dransf. }\end{array}$ & $\begin{array}{l}\text { Palmeira-areca- } \\
\text { bambu }\end{array}$ & Arecaceae & $\mathrm{E}$ & 09 & 0,30 \\
\hline Eugenia uniflora $\mathrm{L}$. & Pitanga & Myrtaceae & $\mathrm{Ma}, \mathrm{Mg}$ & 08 & 0,27 \\
\hline
\end{tabular}

Ci. Fl., Santa Maria, v. 30, n. 4, p. 1019-1031, out./dez. 2020 
Tabela 1 - Conclusão ...

Table 1 - Conclusion ...

\begin{tabular}{lccccc}
\hline \multicolumn{1}{c}{ Nomes Científicos } & $\begin{array}{c}\text { Nomes } \\
\text { Vernaculares }\end{array}$ & Famílias & Origem & $\begin{array}{c}\mathbf{N}^{\circ} \text { de } \\
\text { plantas }\end{array}$ & Dr(\%) \\
\hline $\begin{array}{l}\text { Anadenanthera macrocarpa (Benth.) } \\
\text { Brenan }\end{array}$ & Angico-vermelho & Fabaceae & $\begin{array}{c}\text { Ce, Mg, } \\
\text { Ms }\end{array}$ & 08 & 0,27 \\
Cecropria adenopus Mart. ex Miq. & Embauba & Urticaceae & Am, & 07 & 0,25 \\
Annona muricata L. & Graviola & Annonaceae & Am & 07 & 0,25 \\
$\begin{array}{l}\text { Theobroma grandiflorum } \text { (Willd. ex } \\
\text { Spreng.) K. Schum. }\end{array}$ & Cupuaçu & Malvaceae & Am & 07 & 0,25 \\
$\begin{array}{l}\text { Pachira aquatica Aubl. } \\
\text { Chrysobalanus icaco L. }\end{array}$ & Munguba & Malvaceae & Am & 06 & 0,20 \\
Tamarindus indica L. & Ajurú-rosa & Chrysobalanaceae & Am, Ma & 05 & 0,17 \\
Artocarpus integrifolia L. f. & Tamarindo & Fabaceae & E & 05 & 0,17 \\
Bactris gasipaes Kunth. & Jaca & Moraceae & E & 04 & 0,15 \\
Artocarpus incisa L. & Pupunheira & Arecaceae & Am & 03 & 0,10 \\
\hline
\end{tabular}

Fonte: Autores (2019)

Em que: $\mathrm{Am}=$ Amazônia $\mathrm{Ca}=$ Caatinga $; \mathrm{Ce}=$ Cerrado $\mathrm{E}=$ Exótica; $\mathrm{Ma}=$ Mata Atlântica $\mathrm{Mg}=$ Mata de galeria; $\mathrm{Dr}$ = Densidade relativa. Nomenclaturas baseadas em Lima e Silva Júnior (2010).

Neste estudo cinco famílias botânicas possuem quase a metade $(49,0 \%)$ das espécies observadas na cidade de Monte Alegre. Fabaceae ocorre com 11 espécies (17,2\%), seguida de Arecaceae com sete espécies (10,9\%), Myrtaceae e Anacardiaceae com cinco cada $(7,8 \%)$ e Malvaceae com quatro (6,3\%). Esses resultados corroboram com os observados nos levantamentos realizados nas cidades paraenses de Altamira (PARRY et al., 2012) e Vitória do Xingu (SILVA et al., 2018) e em Aracajú, Sergipe (SANTOS et al., 2015).

O predomínio da família Fabaceae também foi confirmado em outros levantamentos florísticos da arborização de cidades brasileiras: Lima e Silva Júnior (2010) analisaram em seu inventário realizado na cidade de Brasília, que a família Fabaceae foi a mais representativa somando $33(27,5 \%)$ espécies e 1.472 indivíduos $(32,7 \%)$ do total catalogado. Nunes et al. (2013) observaram em Garça, São Paulo, 11 espécies (20\%) e 222 indivíduos (14,6\%). Em Aracajú foram observadas 16 espécies (24,2\%), com 1.096 indivíduos (30,5\%) (SANTOS et al., 2015).

No levantamento da arborização urbana de Monte Alegre - PA foi possível observar também uma diversidade de espécies presentes nas vias públicas, todavia o que chama atenção é que apenas seis espécies contribuem com 1.210 plantas o que representa $41,2 \%$ do total de indivíduos utilizados na arborização, foram elas:Handroanthus serratifolius (Vahl.) S.O. Grose (ipê-amarelo) com 312 indivíduos (10,6\%); Azadirachta indica A. Juss. (nim) com 281 (9,6\%); Syzygium malaccense (L.) Merr \& L. M. Perry (jambeiro) com 181 (6,2\%); Mangifera indica L. (mangueira) e Anacardium occidentale L.(cajueiro) com 155 (5,3\%), respectivamente e Delonix regia (Hook.) Raf. (flamboyant) com 126 indivíduos (4,3\%). Essas espécies também lideram as listas das mais frequentes nos levantamentos realizados por Parry et al. (2012) e Silva et al. (2018), nas cidades de Altamira e Vitória do Xingu, distantes de Monte Alegre, aproximadamente $270 \mathrm{~km}$, ambas as margens do rio Xingu no Pará. Essa predominância de algumas espécies na arborização pode facilitar a instalação e propagação de pragas e doenças, entretanto, se as recomendações básicas para a implantação da arborização forem seguidas, esses eventos serão evitados (BIONDI; LEAL, 2008). 
As 10 espécies exóticas mais observadas no presente estudo são: Azadirachta indica com 281 indivíduos; Syzygium malaccense com 181; Mangifera indica com 155; Delonix regia com 126; Cassia fistula com 94 (3,2\%); Ficus benjamina com 84 (2,9\%); Bougainvillea spectabillis com 63 (2,1\%); Roystonea oleracea com 56 (1,9\%); Plumeria pudica com 47 (1,6\%) e Carica papaya com 46 (1,6\%) indivíduos arbóreos.

Muitas são as cidades onde há a predominância de espécies exóticas em detrimento da flora local. Sabe-se que as espécies nativas são as mais indicadas para formação e manutenção dos corredores ecológicos e outras funções. Diante desse contexto, foi observada a predominância de espécies exóticas em Rorainópolis (RR), por Veloso (2016) e em Parauapebas no Pará, por Ferro et al. (2015), com $62 \%$ e 54\%, respectivamente. As exóticas também foram $62 \%$ em Aracajú (SANTOS et al., 2015). Em contrapartida, em Goiânia (BRASIL, 2008) e Boa Vista (LIMA NETO, 2014) foram observados que 54 e $56 \%$ das espécies eram nativas, respectivamente.

A elevada porcentagem de plantas usadas na arborização da cidade de Monte AlegrePA que não são nativas da região $(72 \%)$ ou do país $(50,0 \%)$ revela a ausência de normas, de planejamento e a falta de técnicas e técnicos especializados em arborização, aliado a falta de informações e pesquisas sobre a conservação da flora nativa local e suas possibilidades de uso. De tal modo, as espécies exóticas não devem ser descartadas, pois também contribuem para a melhoria do clima e a estética, entretanto as espécies nativas regionais devem ser priorizadas (SILVA; CARDOSO; RAPHAEL, 2012).

Foi possível perceber uma pequena participação da população no que diz respeito ao plantio de árvores frutíferas. Dentre as espécies frutíferas mais frequentes estão o jambeiro (Syzygium malaccense) com 181 indivíduos; a mangueira ( $M$. indica) e o cajueiro (A. occidentale) com 155 cada, e a goiabeira ( $P$. guayava) com 85 indivíduos, que juntas representam $19,6 \%$ do total inventariado.

Neste estudo, constatou-se que as árvores frutíferas não são as plantas mais adequadas para a arborização da cidade, por ocasionarem muita sujeira nas vias públicas e por serem mais susceptíveis a pragas, doenças e poluição, problemas esses também observados por Brasil (2008), Ribeiro (2009) e Parry et al. (2012) em seus estudos em Goiânia, Uberlândia e Altamira, respectivamente. Silva, Cardoso e Raphael (2012) indicam que a frutificação das espécies poderá servir de atrativo para a fauna local, na formação dos corredores ecológicos, mas desaconselham espécies que produzam frutos grandes, pois esses frutos podem cair sobre a calçada, veículos ou pedestres.

\section{Análise dos aspectos fitossanitários, de plantio e de manejo}

Com relação à avaliação do porte em que se encontram as plantas da cidade, observou-se que 936 plantas apresentam menos de 5 metros de altura (31,85\%), 1.620 possuem de 5 a 10 metros de altura $(55,15 \%)$ e somente 382 apresentam mais de 10 metros de altura, o que corresponde a 13\%. Esses dados demostram que muitas árvores são jovens (menos de 5 metros de altura) ou que apresentam hábito de crescimento menor (15 espécies), demonstrando que, provavelmente, o plantio tem sido frequente, e ainda que mais da metade das plantas da cidade possui de 5 a 10 metros de altura. Dessa maneira, ocorre uma dominância de árvores bem desenvolvidas, com 49 espécies $(76,6 \%)$ apresentando hábito árvore, quando adultas, porte médio ou grande, o que contribui para uma boa arborização.

Esses resultados não corroboram com os observados por Ferraz et al. (2017), por meio do diagnóstico da arborização urbana de Eldorado - SP, onde constataram que a altura média das árvores foi de 4,90 metros, isso podendo indicar que estas plantas podem ser jovens. Resultados semelhantes também foram observados por Parry et al. (2012) e Silva et al. (2018), nas cidades de Altamira e Vitória do Xingu, respectivamente, quando esses autores encontraram poucas plantas adultas (menos de 10\%) de grande porte. Todos esses autores afirmam que árvores de médio e pequeno porte são apropriadas para ruas de calçadas estreitas e que apresentem fiação aérea, o 
que não foi observado em Monte Alegre, nem nas cidades estudadas pelos autores citados.

Em relação ao diâmetro da copa das plantas em metros, identificou-se que 1.610 indivíduos possuem de 5 a 10 metros, o que representa que 54,8\% das plantas da cidade estão cumprindo com sua principal função, ou seja, o sombreamento das vias públicas.

Em relação às plantas localizadas nos canteiros centrais de ruas e avenidas e nas calçadas, tem-se que: 1.709 plantas estão presentes nos canteiros centrais e 358 nos canteiros das calçadas. $70,4 \%$ dos espécimes estão plantados adequadamente, visto que se encontram no centro dos canteiros. É importante ressaltar que das 632 plantas encontradas em calçadas nas vias públicas da cidade, 195 estavam próximas ao muro $(30,8 \%)$ e $79(12,5 \%)$ junto ao meio fio, o que pode vir a acarretar em danos futuro nas estruturas ou eliminação das plantas. Esses resultados se assemelham ao observado por Silva et al. (2018), na cidade de Vitória de Xingu, onde 68(30\%) plantas estavam próximas aos muros e 24 (11\%) plantas junto ao meio fio.

O presente levantamento permitiu identificar os tipos de canteiros e onde as plantas estão localizadas nas calçadas (Figura 2). Em inúmeros casos as árvores são plantadas em canteiros desproporcionais que acabam prejudicando seus crescimentos e, por vezes, completamente pavimentados.

Figura 2 - Tipos de canteiros e problemas observados na cidade de Monte Alegre, Pará: A) Canteiro de dimensões pequenas; B) Calçada verde com afloramento de raízes; C) Canteiro próximo ao meio fio; D) Colo pavimentado

Figure2 - Types of beds and problems observed in the city of Monte Alegre, Pará: A) Of small dimensions; B) Sidewalk with green outcropping of roots; C) Construction site next to the curb;

D) Paved lap

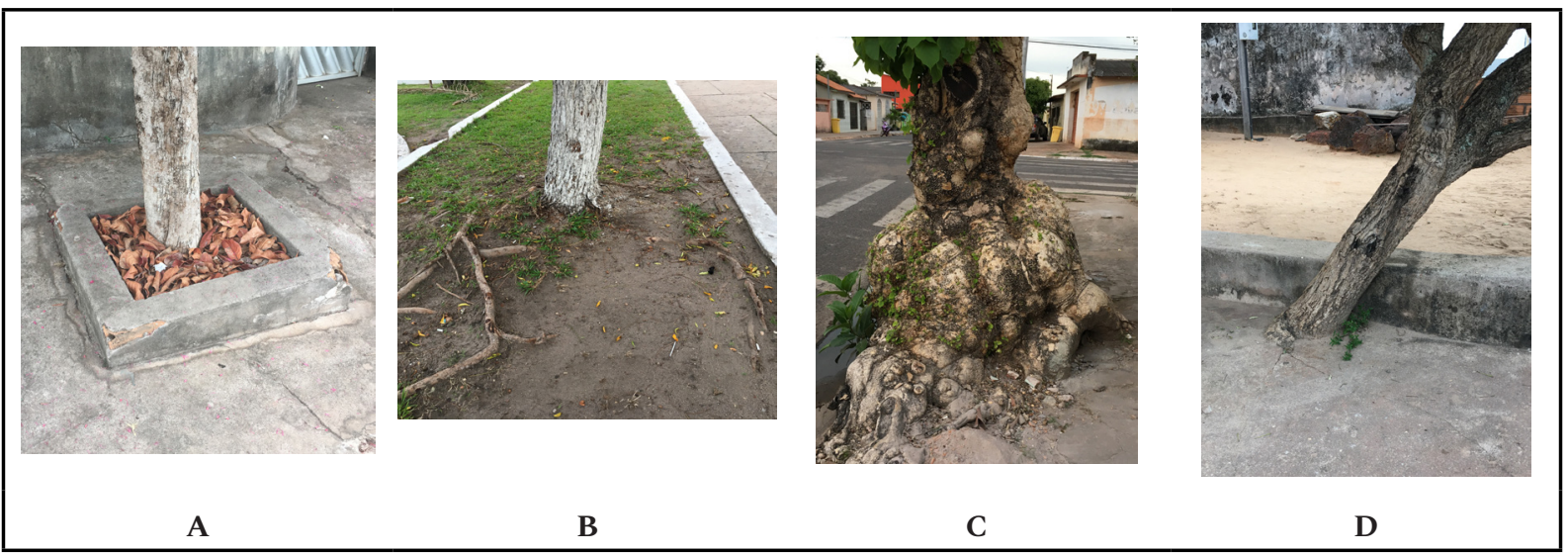

Fonte: Bacelar (2019)

Segundo a Prefeitura de São Paulo (2015), não se recomenda a arborização urbana em calçadas menores de $1,90 \mathrm{~m}$, já que a largura da calçada está correlacionada com o aspecto biológico diâmetro do tronco. Para que as espécies quando adultas não obstruam a área livre do passeio, impedindo, assim, a passagem de pedestres e cadeirantes, não se recomenda o plantio em canteiros menores que $1 \mathrm{~m}^{2}$. Em Monte Alegre, 353 plantas (12\%) estão em canteiros com área inferior a $1 \mathrm{~m}^{2}$, necessitando que esses sejam ampliados.

Averiguou-se que 402 plantas (13,7\%) necessitam de poda leve, ou seja, da remoção de até $25 \%$ da copa, devido seus conflitos com a fiação, iluminação e sinalização de trânsito. Um resultado semelhante foi observado por Parry et al. (2012), em levantamento realizado na cidade de Altamira-PA no qual a poda é o manejo necessário em 574 árvores $(13,4 \%)$ devido aos seus conflitos com a fiação, iluminação e sinalização pública.

No presente estudo foram encontrados problemas relacionados às injúrias e lesões em 
213 plantas, sendo identificadas por vandalismo (149 plantas), representando $70 \%$ das plantas amostradas e poda drástica (64 plantas). O vandalismo também foi mais frequente em 113 indivíduos em Vitória do Xingu e outras 93 plantas apresentaram poda drástica. Ferraz et al. (2017) afirmam que em Eldorado - SP todas as árvores da cidade apresentaram algum tipo de injúria. É importante lembrar que, na maioria das vezes, as injúrias e lesões ocasionadas às plantas ocorrem devido à introdução de espécies não apropriadas para a arborização, como, por exemplo, muitas espécies de Myrtaceae, como S. malaccense (SILVA et al., 2018) ou ainda, quando são plantadas em local impróprio, como em calçadas (PARRY et al., 2012).

Observou-se ainda que 424 árvores $(14,4 \%)$ apresentavam conflitos com a fiação elétrica, 119 plantas (4\%) conflitos com a iluminação pública e 58 árvores $(1,7 \%)$ conflito com a sinalização de trânsito. Em um levantamento da arborização da cidade de Altamira Parry et al. (2012) também encontraram $17,3 \%$ das árvores em conflitos relacionados com a fiação elétrica, iluminação e sinalização das vias. Já Silva et al. (2018) identificaram em seu inventário na cidade de Vitória do Xingu -PA que muitas árvores ( 97 plantas ou $89 \%$ do total) apresentavam conflitos com a fiação elétrica, 12 (11\%) apresentaram conflitos com a iluminação pública e não houve nenhum caso de conflito com sinalização.

Em relação aos conflitos com a fiação elétrica, Silva, Cardoso e Raphael (2012) encontraram em seu estudo um resultado bem expressivo, no qual $55,8 \%$ dos indivíduos que compõem a arborização viária da cidade de Jerônimo Monteiro - ES apresentaram conflito com a rede.

Com base nas observações deste estudo, ficou evidente que 543 plantas estão em conflito ou com a fiação elétrica ou com a iluminação pública. No entanto, com base em pesquisas sobre arborização viária, percebeu-se que a maior frequência de conflitos nas vias públicas das cidades está relacionada à fiação elétrica. Para Pires et al. (2010) as características da fiação são importantes fatores a serem observados no planejamento da arborização urbana e deve ser instalada somente de um lado da via. Além desse fator, recomenda-se que sejam plantadas árvores ou arbustos de pequeno porte, como forma de prevenir e/ou eliminar a interferência dos galhos nessas redes, sem trazer os benefícios esperados de uma arborização ou podar as já existentes, para que não atinjam os fios. Esses cuidados não foram observados na arborização de Monte Alegre.

As injúrias ocasionadas por pragas e doenças foram observadas em 95 plantas, nas quais 55 (1,9\% das plantas totais) apresentaram algum tipo de praga, como formigas, cupins, pulgões e brocas, e 40 plantas (1,3\% do total) apresentaram algum tipo de doença decorrente da incidência de fungos. É interessante ressaltar que foram identificados 2.860 indivíduos com a presença de formigas $(97,35 \%$ do total de plantas), porém essas formigas não foram constituídas como pragas, já que eram meras visitantes.

Diante disso, ressalta-se um percentual elevado de árvores em boas condições fitossanitárias na cidade, visto que apenas 95 indivíduos ( $3,2 \%$ do total) foram detectados com algum tipo de praga ou doença. Esse resultado se assemelha à situação constatada por Paula e Melo (2010) na cidade de Planalto - SP, onde 85,3\% das árvores não apresentavam injúrias mecânicas ou doenças aparentes.

Ainda em relação aos conflitos observados nas vias públicas da cidade, identificou-se que 58 indivíduos apresentam algum tipo de conflito com a sinalização de trânsito. Apesar de ser um número pouco expressivo (menos de $2 \%$ do total de plantas), não deixa de ser um fato preocupante, já que essa situação tem causado sérios problemas para a cidade de Monte Alegre, devido às árvores não possuírem a distância recomendada das esquinas e se localizarem, geralmente, em ruas de maior trânsito de veículos e pedestres.

De fato, deve-se entender que a arborização urbana não significa apenas plantar árvores de modo aleatório em qualquer lugar, pois quando elas alcançarem a idade adulta poderão causar problemas, tais como aqueles identificados na cidade de Monte Alegre. Assim, compreendese que é de competência do poder público municipal promover e executar ações que visem à preservação, recuperação e ampliação da arborização urbana de acompanhamento viário. É necessária a adoção de um planejamento estratégico e a gestão continuada para a arborização. 
Sugestão de ações, incluindo o monitoramento sistemático, poda, remoção, combate a pragas e doenças, substituição e plantio poderão contribuir para garantir os benefícios ambientais e paisagísticos da arborização para o bem-estar da população.

Neste estudo foi feito o levantamento da arborização presente nas vias públicas de todos os dezessete bairros da cidade, no entanto em três deles, Nova Olinda, Nova União e Camarazinho, por se tratarem de bairros formados recentemente, não foram observadas nenhuma atividade de infra estrutura por parte da Prefeitura Municipal, uma vez que esses bairros ainda não possuem rede de abastecimento de água, esgoto, iluminação pública, tão pouco, pavimentação das vias, sinalização de trânsito e arborização. Desse modo, observou-se a presença de árvores nos seguintes bairros, conforme constam os dados apresentados na Tabela 2.

Tabela 2 - Número de plantas encontradas por bairro, nas vias públicas da cidade de Monte Alegre, Pará

Table 2 - Number of plants found by neighborhood, on public road in the city of Monte Alegre, Pará

\begin{tabular}{lclc}
\hline \multicolumn{1}{c}{ Bairros } & Número de Plantas & \multicolumn{1}{c}{ Bairros } & Número de Plantas \\
\hline Cidade Alta & 396 & Curaxi II & 147 \\
Pajuçara & 387 & Serra Oriental & 141 \\
Planalto & 296 & Cidade Baixa & 100 \\
Terra Amarela & 288 & Turu & 94 \\
Centro & 246 & Papagaio & 84 \\
Serra Ocidental & 226 & Camarazinho & - \\
Curaxi & 184 & Nova Olinda & - \\
Curitanfã & 177 & Nova União & - \\
Surubeju & 172 & Total Geral & 2.938 \\
\hline
\end{tabular}

Fonte: Bacelar (2019)

Mediante esses dados averiguou-se que os bairros mais arborizados são Cidade Alta e Pajuçara, com 396 e 387 plantas respectivamente. Nesse contexto, a presença de plantas em maior número nesses dois bairros se dá pelo fato de serem antigos e por serem residenciais. Outro bairro bastante arborizado é o Planalto, com 296 plantas, que apesar de ser um bairro formado recentemente, possui um número expressivo de árvores. O bairro Cidade Baixa é um dos bairros mais antigos da cidade, porém é um dos menos arborizados, com apenas 100 plantas. Isso pode ser explicado pelo fato deste ser um bairro comercial. Esses resultados corroboram com os observados por Parry et al. (2012) e Silva et al. (2018).

\section{Conclusões}

Existem alguns conflitos promovidos pela arborização, causados em grande parte pelas espécies exóticas, isso decorrente da falta de planejamento e um Plano Diretor, causando danos aos bens públicos e privados.

Há a necessidade de que os profissionais habilitados, o poder público municipal e demais setores responsáveis pela arborização urbana da cidade atuem de forma conjunta e eficiente, de acordo com as leis pertinentes.

É importante que a Prefeitura Municipal realize as benfeitorias necessárias nos bairros 
de Nova Olinda, Nova União e Camarazinho, promovendo o saneamento básico, instalando a iluminação pública, a pavimentação das vias e suas sinalizações de trânsito, e priorize as ações de arborização urbana.

\section{Referências}

ANGIOSPERM PHYLOGENY GROUP. An update of the Angiosperm Phylogeny Group classification for the orders and families of flowering plants: APG IV. Botanical Journal of the Linnean Society, [s.1.], n. 181, p. 1-20, 2016.

BRASIL. Instrução normativa n.o 30, de 05 de setembro de 2008. Institui o Plano Diretor Arborização Urbana de Goiânia. Diário oficial [do] município de Goiânia, Poder executivo, Goiás, GO, n. 4.461, 30 set. 2008, Seção 1, p. 2, 2008.

BIONDI, D.; LEAL, L. Caracterização das plantas produzidas no Horto Municipal de Barreirinha, Curitiba/PR. Revista da Sociedade Brasileira de Arborização Urbana, Piracicaba, SP, v. 3, n. 2, p. 20-36, 2008.

CAMPOS FILHO, E. M. Coleção plante as árvores do Xingu e Araguaia: guia de identificação. v. II. São Paulo: Instituto Socioambiental, p. 20-214, 2009.

CARVALHO, R. B. Introdução aos Estudos Amazônicos para o Município de Monte Alegre PA. 1.ed. Santarém-Pará: Gráfica e Editora Brasil, p. 59, 2015.

FERRAZ, M. V. et al. Diagnóstico da arborização urbana de Eldorado - SP. Revista Tree Dimensional, ProFloresta, Goiânia, v. 2, n.4, p. 22, 2017.

FERRO, C. C. S. et al. Inventário quali-quantitativo da arborização viária de um trecho da rodovia PA-275 no município de Parauapebas - PA. Revista da Sociedade Brasileira de Arborização Urbana, Piracicaba, SP, v. 10, n. 3, p. 73-84, 2015.

FIDALGO, O.; BONONI, V. L. R. Técnicas de coleta, preservação e herborização de material botânico. São Paulo: Instituto de Botânica, 1989. 62p. (Instituto de Botânica, Documento).

FORZZA, R. C.; LEITMAN, P. M.; COSTA, A. F. Introdução. In: Lista de Espécies da Flora do Brasil. Jardim Botânico do Rio de Janeiro. 2010. Disponível em: http://floradobrasil.jbrj.gov. br/2010. Acesso em: 10 out. 2017.

INSTITUTO BRASILEIRO DE GEOGRAFIA E ESTATÍSTICA (IBGE). Estimativa Populacional 2016 (PDF). Disponível em: http://www.ibge.gov.br/Estimativas_de_população/ Estimativas_2016/estimativa_dou_2016_20160913.pdf. Acesso em: 21 set. 2017.

LIMA NETO, E. M. Índices e métricas para a gestão de árvores de rua de Boa Vista - RR a partir de cadastro espacial. 2014. 167f. Tese (Doutorado em Engenharia Florestal) - Ciências Agrárias, Universidade Federal do Paraná, Curitiba, 2014.

LIMA, R. M. C.; SILVA JÚNIOR, M. C. Inventário da arborização urbana implantada na década de 60 no plano piloto, Brasília, DF. Revista Brasileira de Arborização Urbana, Piracicaba, SP, v. 5, n. 4, p. 110-127, 2010.

MILANO, M. A. Avaliação e análise da arborização de ruas de Curitiba - PR. 1984. 154 f. Dissertação de Mestrado (Mestrado em Engenharia Florestal) - Ciências Agrárias, Universidade Federal do Paraná, Curitiba, 1984.

NUNES. R. L. et al. Levantamento qualiquantitativo da arborização urbana do bairro Ferraropólis na cidade de Garça, SP. Revista Brasileira de Arborização Urbana, Piracicaba, SP, v. 8, n. 1, p. 65-74, 2013.

PARRY, M. M. et al. Composição Florística da Arborização da Cidade de Altamira-Pará. Revista 
da Sociedade Brasileira de Arborização Urbana, Piracicaba, SP, v. 7, n. 1, p. 143-158, 2012.

PAULA, D. S.; MELO, A. G. C. Levantamento quali-quantivativo da arborização urbana do município de Planalto, SP. Revista Científica Eletrônica de Engenharia Florestal, Garça, SP, v. 16, n. 1, p. 64-81, 2010.

PIRES, N. A. M. T. et al. A arborização urbana do município de Goiandira, GO - caracterização quali-quantitativa e propostas de manejo. Revista da Sociedade Brasileira de Arborização Urbana, Piracicaba, v. 5, n. 3, p. 185-205, 2010.

PREFEITURA DE SÃO PAULO. Manual técnico de arborização urbana, 2015. Disponível em: http://www.prefeitura.sp.gov.br/cidade/secretarias/upload/meio_ambiente/MARBOURB.pdf. Acesso em: 05 jan. 2018.

RIBEIRO, F. A. B. S. Arborização urbana em Uberlândia: percepção da população. Revista da Católica. Uberlândia, v. 1, n. 1, p. 224-237, 2009. Disponível em: http://www.catolicaonline.com. br/revistadacatolica. Acesso em: 10 nov. 2017.

SANTOS, C. Z. A. et al. Análise qualitativa da arborização urbana de 25 vias públicas da cidade de Aracajú, SE. Ciência Florestal, Santa Maria, v. 25, n. 3, p. 751-763, 2015.

SEGAWA, H. Arquitetura paisagística até 1930. In: FARAH, I.; SCHLEE, M. B.; TARDIN, R. (orgs.) Arquitetura paisagística contemporânea no Brasil. São Paulo: SENAC, p. 35-48, 2010.

SILVA, A. G.; CARDOSO, A. L.; RAPHAEL, M. Diagnóstico quali-quantitativo da arborização viária da cidade de Jerônimo Monteiro, ES. Enciclopédia Biosfera, Centro Científico Conhecer, Goiânia, v. 8, n. 14, p. 1179, 2012.

SILVA, L. A. et al. Diagnóstico da arborização urbana da cidade de Vitória do Xingu, Pará, Brasil. Revista da Sociedade Brasileira de Arborização Urbana, Piracicaba, SP: v. 13, n. 1, p. 57-72, 2018.

VELOSO, J. N. Inventário da arborização das principais avenidas do município de Rorainópolis, Roraima. Boletim do Museu Integrado de Roraima, Roraima, RR, v. 10, n. 2, p. 28-40, 2016. 